\title{
Data Mining for Information Literacy
}

\author{
Bettina Berendt \\ Department of Computer Science, K.U. Leuven, B-3001 Heverlee, Belgium; \\ http://www.cs.kuleuven.be/ berendt
}

In: Dawn E. Holmes and Lakhmi C. Jain. (Eds.),

Data Mining: Foundations and Intelligent Paradigms. Volume 3: Medical, Health,

Social, Biological and other Applications (pp. 265-297). Springer 2012.

\begin{abstract}
This paper argues for extending the scope of applying data mining towards making it a means to help people better understand, reflect and influence the information and information-producing and -consuming activities that they are surrounded by in today's knowledge societies. Data mining is thereby seen as a means to furthering information literacy and specifically critical literacy. We discuss and extend classical definitions of these two constructs and derive critical data literacy and privacy literacy as two essential new key sub-competences. We describe an analysis framework for concrete efforts to use data mining in this way, structuring by techniques and objects and characterising by how principles of successful learning are supported. We then analyse a number of examples of current Web-based tools within this framework, investigating how they can further critical data literacy and privacy literacy. We conclude with an outlook on next steps in the proposed new field of Data Mining for Information Literacy.
\end{abstract}

Keywords: Web mining, text mining, knowledge discovery, learning, information literacy, privacy

\section{Introduction}

When one thinks of Data Mining, it is usually as a family of automated techniques for sifting through huge amounts of data in order to find "nuggets" of knowledge. These can be deployed directly in an application such as the buying recommendations in online bookstores or the ranking of results in Web search engines [32]. Alternatively, they are used to support managements via business analytics, for example to identify high-value customers or detect credit-card fraud [11]. Governments may use data mining for identifying suspicious individuals [54].

So who are the primary beneficiaries of Data Mining (DM)? In the businessanalytics and national-security application areas, they are businesses and governments, while (some) customers and citizens profit from increased efficiency and security. In business models where DM "is" the product (such as recommender systems or search engines), there is also a rather straightforward advantage for customers/users in terms of functionality. But can we go beyond this view that 
focuses on people as customers or advertising consumers? The purpose of this paper is to argue that data mining can do much more, that it can be a highly effective means for making people aware of the nature, potential and limitations of the information they are surrounded by - and that they themselves constantly produce; that this has important social and democratic aspects; thus, in short, that data mining can be serve as a tool for furthering information literacy.

Much has been said about the potentials for education and democracy of the Internet and specifically the Web, e.g. [26]. When one of the goals is democracy, is it enough for a society to make the Internet widely and cheaply available, to teach school children (and interested citizens) how to use it, to install e-Government services, allow for online petitions, and allow free speech in blogging sites? Arguably, such a mainly technological approach is not sufficient; democracy also needs a culture of democratic behaviour in the informational environment of the respective society. But what does this mean? Along with Shapiro and Hughes [52], we ask:

"What does a person need to know today to be a full-fledged, competent and literate member of the information society? As we witness not only the saturation of our daily lives with information organized and transmitted via information technology, but the way in which public issues and social life increasingly are affected by information-technology issues - from intellectual property to privacy and the structure of work to entertainment, art and fantasy life - the issue of what it means to be information-literate becomes more acute for our whole society. Should everyone take a course in creating a Web page, computer programming, TCP/IP protocols or multimedia authoring? Or are we looking at a broader and deeper challenge - to rethink our entire educational curriculum in terms of information?"

Based on these questions, the authors propose to re-define the long-used concept of information literacy to extend beyond the narrow notion of knowing how to use a library or search on the Web.

"Or is [information literacy] [...] something broader, something that enables individuals not only to use information and information technology effectively and adapt to their constant changes but also to think critically about the entire information enterprise and information society? Something more akin to a 'liberal art' - knowledge that is part of what it means to be a free person in the present historical context of the dawn of the information age?"

This notion of information literacy is closely linked to education and its main goal in the sense of Dewey [17, pp. 76ff.]: increasing the ability to perceive and act on meaning in one's society, advancing students' ability to understand, articulate, and act democratically in their social experience. We will therefore base the remainder of this article on pertinent background in educational studies (Section 2), propose a framework derived from these to structure and characterize concrete tools (Section 3), and use this framework to analyze a number of 
data-mining and other data collection and analysis efforts as examples of "data mining for information literacy" (Section 4). These are, for reasons of space, exemplary and not meant to be a comprehensive survey. Section 5 concludes with an outlook.

\section{Background}

We build on the notions of information literacy and critical literacy as defined by Shapiro and Hughes [52] and Shor [53]. Both are intimately linked with educational approaches for achieving this kind of literacy. The combination of data mining and education has some touchpoints with the emerging field of Educational Data Mining.

\subsection{Information literacy}

Shapiro and Hughes [52] propose the following dimensions of information literacy as a sketch for a curriculum:

"Tool literacy , or the ability to understand and use the practical and conceptual tools of current information technology, including software, hardware and multimedia, that are relevant to education and the areas of work and professional life that the individual expects to inhabit.

Resource literacy, or the ability to understand the form, format, location and access methods of information resources, especially daily expanding networked information resources. This is practically identical with librarians' conceptions of information literacy, and includes concepts of the classification and organization of such resources.

Social-structural literacy , or knowing that and how information is socially situated and produced. This means knowing about how information fits into the life of groups; about the institutions and social networks - such as the universities, libraries, researcher communities, corporations, government agencies, community groups - that create and organize information and knowledge; and the social processes through which it is generated - such as the trajectory of publication of scholarly articles (peer review, etc.), the relationship between a Listserv and a shared interest group, or the audience served by a specialized library or Web site.

Research literacy, or the ability to understand and use the IT-based tools relevant to the work of today's researcher and scholar. For those in graduate education, this would include discipline-related computer software for quantitative analysis, qualitative analysis and simulation, as well as an understanding of the conceptual and analytical limitations of such software. 
Publishing literacy, or the ability to format and publish research and ideas electronically, in textual and multimedia forms (including via World Wide Web, electronic mail and distribution lists, and CD-ROMs), to introduce them into the electronic public realm and the electronic community of scholars. Writing is always shaped by its tools and its audience. Computer tools and network audiences represent genuine changes in writing itself.

Emerging technology literacy, or the ability to ongoingly adapt to, understand, evaluate and make use of the continually emerging innovations in information technology so as not to be a prisoner of prior tools and resources, and to make intelligent decisions about the adoption of new ones. Clearly this includes understanding of the human, organizational and social context of technologies as well as criteria for their evaluation.

Critical literacy, or the ability to evaluate critically the intellectual, human and social strengths and weaknesses, potentials and limits, benefits and costs of information technologies. [...] This would need to include a historical perspective (e.g. the connection between algorithmic thinking, formalization in mathematics, and the development of Western science and rationality and their limits); a philosophical perspective (current debates in the philosophy of technology, the critique of instrumental reason, the possibility and nature of artificial intelligence); a sociopolitical perspective (e.g. the impact of information technology on work, public policy issues in the development of a global information infrastructure); and a cultural perspective (e.g. current discussions of the virtual body and of the definition of human being as an information-processing machine)."

Revisiting the brief comments made in the Introduction about DM in "everyday tools", one can see that the use of DM is today clearly a part of tool literacy and to some extent resource literacy for everyone. For example, people need to know how to use a search engine and have at least some knowledge about how to interpret a ranking (e.g., knowing that popular sites come first) and how to get the underlying resources, whether they are online (and may need a browser plugin to be viewed) or offline (and may require a visit to a local library). However, in using such tools, people are merely consumers of fixed DM applications and do not attain much in-depth knowledge about their workings, side effects, etc. Such knowledge tends to be imparted mainly in advanced computer-science courses that take detailed looks at underlying algorithms, weaknesses, attacks (such as "Google bombs" or "sybil attacks" on recommender systems ${ }^{1}$ ). Thus, for these students DM is part of the research literacy taught in Artificial Intelligence, Databases or Statistics courses.

\footnotetext{
${ }^{1}$ Google bombing (also known as search-engine bombing or link bombing) refers to practices that influence the ranking of particular pages in results. In a sybil attack, an attacker subverts a reputation system by creating a large number of pseudonymous entities, using them to gain a disproportionately large influence.
} 
Going beyond this, we here want to argue - and put forward as a research programme - that DM also has the potential to become an essential part of critical literacy for a wider audience. To understand why, we want to go into Shor's [53] understanding of critical literacy. These considerations will show that when used like this, DM can also be an important part of socio-structural literacy (a dimension from [52] that is arguably not separable from critical literacy in the [53] sense). Further, in Sections 4.4 and 4.5, we will argue that the 1996 notion of publishing literacy needs to be extended to also comprise decisions not to publish something, and that DM has a key role to play in the development of such a privacy literacy. It is to be hoped that curricula for teaching DM with respect to information literacy in this way will be sufficiently up-to-date regarding current developments and thereby contribute also to emerging-technology literacy.

\subsection{Critical literacy}

Shor [53] defines critical literacy as "[habits] of thought, reading, writing, and speaking which go beneath surface meaning, first impressions, dominant myths, official pronouncements, traditional clichés, received wisdom, and mere opinions, to understand the deep meaning, root causes, social context, ideology, and personal consequences of any action, event, object, process, organization, experience, text, subject matter, policy, mass media, or discourse".

For Shor, the motivation for this is clearly humanistic and political: "Critical literacy involves questioning received knowledge and immediate experience with the goal of challenging inequality and developing an activist citizenry." This perspective implies that information (critical) literacy be a part of general education; and this could happen at every level, adapted to the respective students' intellectual and political knowledge, motivation and possibilities.

When one considers how critical literacy expresses itself in behaviours, the close link to education becomes clear: "Critical literacy can be thought of as a social practice in itself and as a tool for the study of other social practices. That is, critical literacy is reflective and reflexive: Language use and education are social practices used to critically study all social practices including the social practices of language use and education. Globally, this literate practice seeks the larger cultural context of any specific situation. 'Only as we interpret school activities with reference to the larger circle of social activities to which they relate do we find any standard for judging their moral significance,' Dewey wrote (Moral Principles in Education, 13)." Shor then investigates the case in which this "how" is taught and learned in settings that (a) are curricular courses, (b) deal intrinsically with language-as-practice, and (c) leave a certain extent of freedom. These he finds in (language) composition classes.

The goal of language composition classes is to teach students how to understand and use language - viewed as a primary means of human communication and knowledge transfer - to the best of their abilities. Our fundamental assumption is that today, the presentation of numbers or other data and their analyses by mathematical-statistical models and/or visualization techniques has become 
a second very important form of human communication, such that "data analysis" is by now as much of a "social practice" as language. ${ }^{2}$ We will henceforth refer to Shor's notion as critical language literacy and to our new notion as critical data literacy. Thus, rephrasing Shor, we can formulate our vision: "Critical data literacy is reflective and reflexive: Uses of data analysis are social practices used to critically study all social practices including the social practices of data analysis".

\subsection{Educational Data Mining}

The combination of data mining and education also evokes Educational Data Mining (EDM). This is "an emerging discipline concerned with developing methods for exploring the unique types of data that come from an educational context. Given the widespread use of e-learning and the vast amount of data accumulated recently, researchers in various fields have begun to investigate data mining methods to improve e-learning systems." [50]. Thus, EDM can be said to focus on "data mining of data from educational processes", while we are interested in "data mining for learning processes". These two approaches are not mutually exclusive, one example is the use of data mining for personalization in e-Learning, see [3] for a recent literature overview. However, in contrast to current EDM, we focus on the learner actively and consciously performing data mining techniques (data mining as a social practice), and we treat data analysis as an important topic/object of teaching and learning in knowledge societies. We believe that an exploration of similarities and differences between EDM and our vision can be very fruitful for theory and education; this will be the topic of future work.

\section{Towards critical data literacy: a frame for analysis and design}

Based on the related work on information and critical language literacy, we now want to design a framework for identifying and classifying tools and their use that could help foster critical data literacy. Of course, natural language remains remains dominant for most communicational and rhetorical purposes; thus efforts aimed at critical data literacy should not displace, but augment those aimed at critical language literacy. (In fact, a thorough understanding of "how to lie with statistics", i.e. common misconceptions, misinterpretations of information visualizations, etc. is an essential basis for optimal use and understanding of such tools!) In a second step, we will then propose criteria by which the learning effectiveness of tools can be characterized.

\subsection{A frame of analysis: technique and object}

One way of structuring solution proposals (such as tools) that can contribute to Data Mining for Information Literacy is by their primary technique and object in

\footnotetext{
${ }^{2}$ Note that we will treat data mining as a special form of data analysis, preferentially using the latter term for its generality.
} 
the sense of Shor's definition of critical literacy. When language (and education) are the technique as well as the object of analysis, the analysis is an activity that can foster critical language literacy sensu Shor. The archetypal critical data literacy would then involve data analysis as technique and as object. However, a wider look at different types of objects and combinations can yield more insights; consider in particular the following (of which the last four will be the topic of the present paper):

Language as technique, anything as object: This is a typical approach of basic essay writing (which could be a first step in a basic composition class, a prerequisite for later activities designed to foster critical literacy).

Language as technique, data analysis as object: this is the approach taken by a large range of writing designed to foster students' or the public's understanding of statistics. It ranges from books such as [25] about common errors, both intentional and unintentional, associated with the interpretation of statistics, and the incorrect conclusions that can follow from them which has become one of the most widely read statistics books in history -, to specific media-critical observations like [39] about persistently incorrect interpretations and their wide and uncritical take-up by other media.

Data analysis as technique, anything as object: This is a typical approach of basic statistics or data mining classes. In Section 4.1, we show examples of Web-based tools that make this available to everyone in an engaging, thought-provoking and user-friendly way.

Data analysis as technique, language as object: an approach followed by information retrieval, text mining, and corpus linguistics (see e.g. Introduction). In Section 4.2, we will investigate different tools whose goal is a critical analysis of texts.

Data analysis as technique, data analysis as object: A "pure" form of critical data literacy that probably requires the most abstraction capabilities. To the best of our knowledge, this is not very wide-spread yet. An example will be described in Section 4.3.

Data analysis as technique, behaviour in data spaces as object: This combination has created much novelty and interest in recent years, probably since behaviours in data spaces like the Internet are increasingly "authentic/situated" behaviours of many people. Sections 4.4 and 4.5 will discuss Web-based tools whose goal is a critical analysis of such behaviours.

As for language use, education appears to be the adequate cultural environment for this. This could range from the integration into the school or university curriculum to uptake by adult-education institutions and other voluntary, semiformal settings. The Web appears to be a very well-suited medial environment for the storage, transfer, and use of such learning activities, but like in other areas, an approach that solely relies on autodidactic approaches appears risky. Data analysis is an activity best done with the help of software, thus, we focus 
on (usually Web-based) software tools as cognitive tools. ${ }^{3}$ (Thus, the use and ideally also creation of tools becomes the analogue of natural-language use.)

\subsection{On the chances of achieving critical data literacy: Principles of successful learning as description criteria}

Modern learning theories name the following principles of successful learning ${ }^{4}$

1. It is situated and authentic; multiple contexts are investigated.

2. It is active and constructive.

3. Multiple perspectives are taken.

4. It is social.

5. It involves articulation and reflection.

Principle 1 is very relative to what interests a learner - "situated" is often thought of being about one's "natural environment", but this is very different for different learners, and an avid mathematician (for example) may "live" in a mathematics world. The investigation of multiple contexts is relevant to support transfer learning. All these demands can be met easily with the Web - data and questions to the data that 'matter' to the learners can be chosen from the vast array of possibilities. We will focus on current-events topics as likely to be interesting to a wide range of (news-consuming) people.

Principle 2 is given with data-analysis tools: Learners take an active role in defining and performing analyses, and they construct new representations (such as classifiers from data). However, the true extent of constructiveness and freedom of re-representation needs to be investigated for each case.

Principle 3 is not automatically given. We will investigate below how data mining can support the exploration of and creation of different perspectives. Note the 'playful' element of such role-playing activities (today often referred to as "identity management"), which is considered highly important for intellectual flexibility and even successful behaviour in societies [51].

Principle 4 is a key point of the Social Web. It is realized mainly through today's extensive social networks, in which people are free (and often quite active) in commenting on each other's utterances and extending on them. Note, however, that this is not automatically given just by offering a tool; in an educational setting, appropriate instructions can help to realize it.

\footnotetext{
3 'The term 'cognitive tools' was coined by the book edited by Lajoie and Derry [29] [... : ] computers could support learning by explicitly supporting or representing cognitive processes. In such a sense computers could serve as being a 'mind extension', augmenting the limited capacity of the brain. More general we can define cognitive tools as being instruments that are designed for supporting cognitive processes and thereby extending the limits of the human cognitive capacities. In principle anything can be a cognitive tool, for instance a sheet of paper and a pencil can be a cognitive tool to support the cognitive process of remembering items, extending the limited capacity of working memory." [58, p. 389]

4 This list is my own summary of relevant findings from (social) constructivism and constructionism, based on sources such as $[1,14,28,36,43,59,61,64]$.
} 
Principle 5 requires two things: To articulate content, one needs to represent it, for example in words, by a drawing, etc. It is well known from the cognitive and learning sciences that a mere repetition of a given representation is usually not effective, that rather, a different re-representation is helpful and often necessary to gain insights, solve problems, etc. [41]. Reflection involves the inspection and active construction of such re-representations and in general meta-cognitive strategies for managing the learning process [49].

We will use these five principles as criteria for the characterization of the case studies / tool examples to be presented in the following section. In addition, we will use Criterion

6. Data mining sophistication, in order to gauge to what extent the examples use the power of state-of-the-art data mining.

\section{Examples: Tools and other approaches supporting data mining for information literacy}

In the following, we will analyse different examples of current-day uses of data mining for critical data literacy as defined above. They will be ordered by their primary technique and object as laid out in Section 3.1, and characterized by the six criteria as laid out in Section 3.2. Both perspectives are designed to outline what current tools can do and what is missing most.

\subsection{Analysing data: Do-it-yourself statistics visualization}
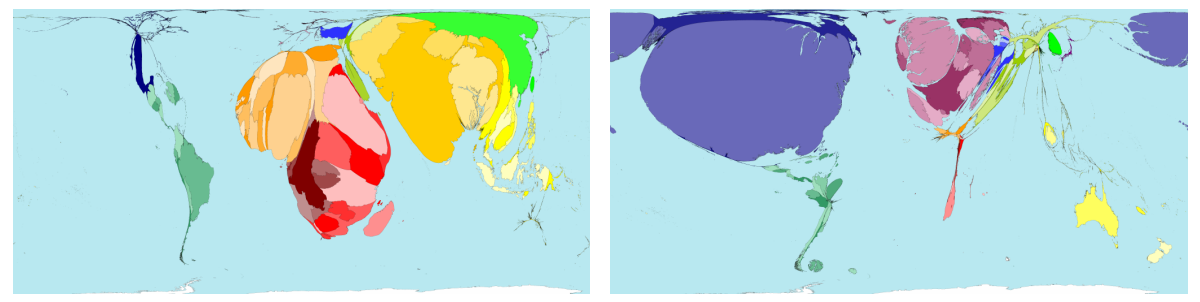

Fig. 1. Worldmapper: Child labour (left) and Toys imports (right). ${ }^{5}$

The press is full of information graphics about current events, and "smart graphics" can be "worth a thousand words". Thematic maps are maps that focus not on the geographic features of countries and other regions, but on political, social or economic quantities that characterize those regions. They become especially interesting when innovative visualization strategies are chosen.

\footnotetext{
${ }^{5}$ from http://www. worldmapper.org, retrieved on 2010-07-30.
} 
The site www.worldmapper.org transforms each country's area by a quantity associated with that country. Technically, Worldmapper is a collection of world maps, using equal area cartograms where territories are re-sized on each map according to a particular variable. One example is population. In addition, juxtapositions and animations can show how these relationships between countries differ when different statistics are chosen, such as the one shown in Fig. 1. Some additional features such as interactive maps that support zooming and panning are offered for some datasets. The site contains 696 maps, with associated information and PDF 'poster' file. Each map relates to a particular subject. Data files that underlie the maps can be downloaded in a popular and interoperable format (Excel). The project is a collaboration of researchers and practitioners at the universities of Sheffield and Michigan, the Leverhulme Trust and the Geographical Association. The data were mostly supplied by the UN.

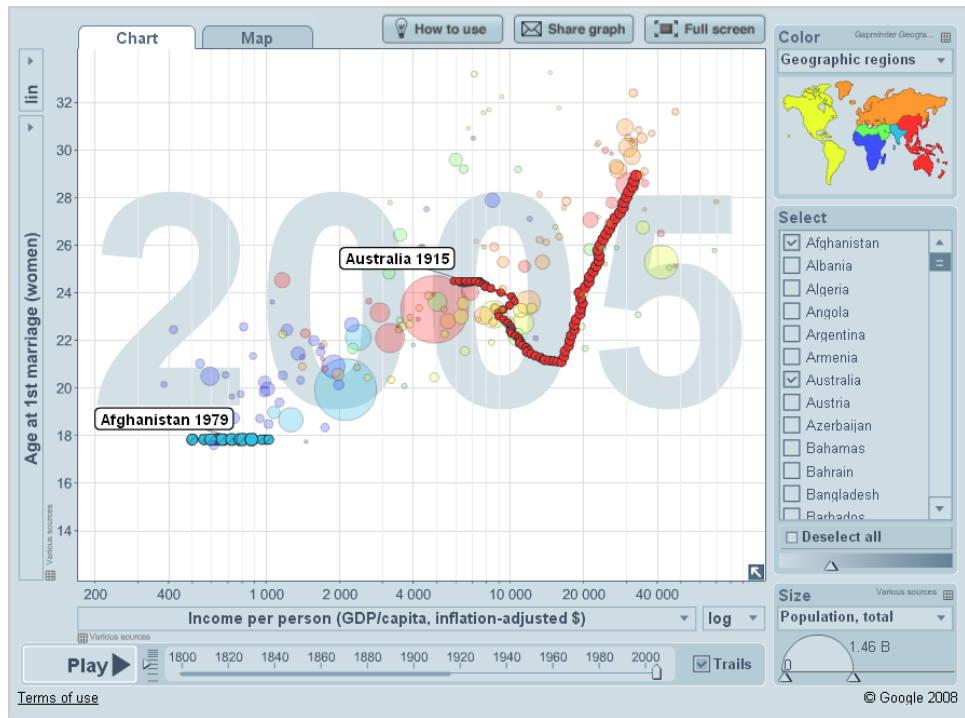

Fig. 2. Gapminder: income vs. age at first marriage, Australia vs. Afghanistan, tracking years shown as circles. Snapshot taken at the end of animation. ${ }^{7}$

www.gapminder.org offers a software that allows one to plot various timeseries and contrast them. Its goal is to "unveil the beauty of statistics for a fact based world view". Data come from official sources like the OECD or the International Labor Organization. Fig. 2 shows an example. Different options of overview and detail sequences and zooming and changing between representations (e.g. chart or tabular) are offered. GapMinder is available as an online version and as an offline desktop version. Different output formats such as videos,

\footnotetext{
7 from http://www.gapminder.org, retrieved on 2010-07-30.
} 
Flash or PDF are supported. A plugin in GoogleDocs makes it possible to create these graphs with one's own data. ${ }^{8}$ Special attention is paid to the needs of teachers or others who want to use GapMinder for their own presentations. GapMinder was created as a Foundation in Sweden and was bought by Google in 2007, where the original developers continue to work.

An analysis along our six principles reveals the following.

1. Situatedness and authenticity, multiple contexts Both tools apply statistics and data visualization to authentic official data that are clearly situated in systems of development indicators and official statistics. Multiple contexts are supported by different datasets.

2. Active and constructive In Worldmapper, activity is basically limited to choosing graphs; in GapMinder, further interaction options (like the selection of countries) support a stronger sense of user activity and choice. Activity is more strongly supported by GapMinder when users choose their own datasets. A sense of construction can be created in the sense that one transforms relational tables into graphics; although the constructive element is limited by the available analysis options.

3. Multiple perspectives Multiple perspectives could be supported by the choice of different but complementary indicators of a common thematic complex (e.g. girls' illiteracy and child labour as indicators of poverty, or prevalence of diseases and alcohol consumption as indicators of health status). More challenging appears to be the use of different datasets that operationalize the same construct in different ways, collected by different agents - this could stimulate discussions on multiple perspectives more strongly. The latter is only supported by tools such as GapMinder that allow users to visualize datasets of their own choosing.

4. Social Beyond the sharing of graphs/analysis results, the tools offer no specific social usage models. Sharing is supported by GapMinder in a common Web2.0 fashion: a link that supplies a URL to be inserted into a website or email. Sharing and joint editing via GoogleDocs could be a basis for further social usage models.

5. Articulation and reflection The visualizations and especially the juxtapositions offer re-representations of tabular and quantitative data; as such, they articulate and re-represent. This can arguably be highly conducive to reflection and the discovery of new solutions in the sense of successful information visualizations or visual data mining.

\footnotetext{
8 http://www .gapminder.org/upload-data/motion-chart/

10 http://flowingdata.com/wp-content/uploads/2007/09/snow_cholera_ mapsm.jpg; http://www.evl.uic.edu/luc/422/GIFs/challenger2.gif, see $[56, \quad$ p. 47] http://revcompany.com/blog/wp-content/uploads/2009/08/ challenger-disaster.gif, adapted from [56, p. 45]; retrieved on 2010-07-30.
} 


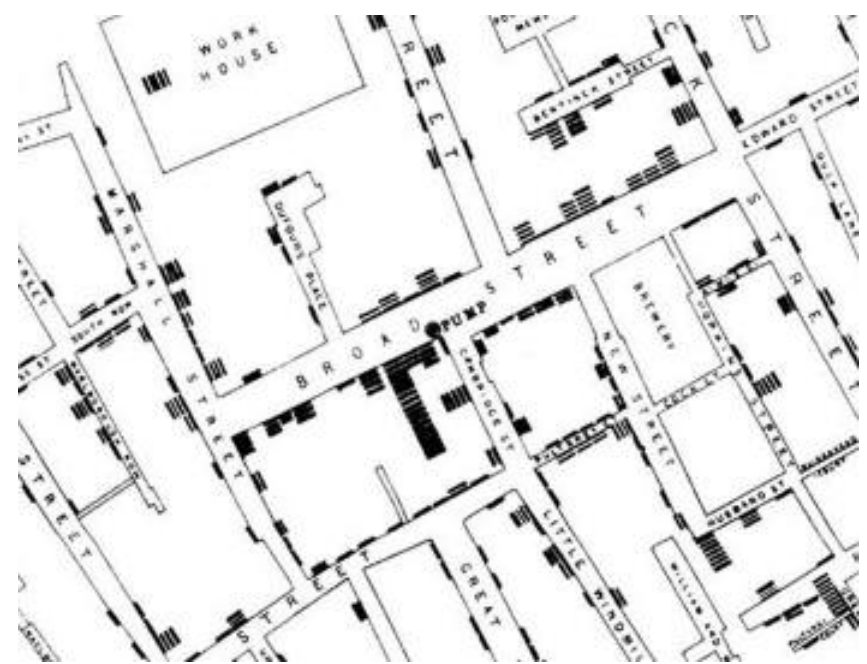

History of O-Ring Damage in Field Joints (Cont)
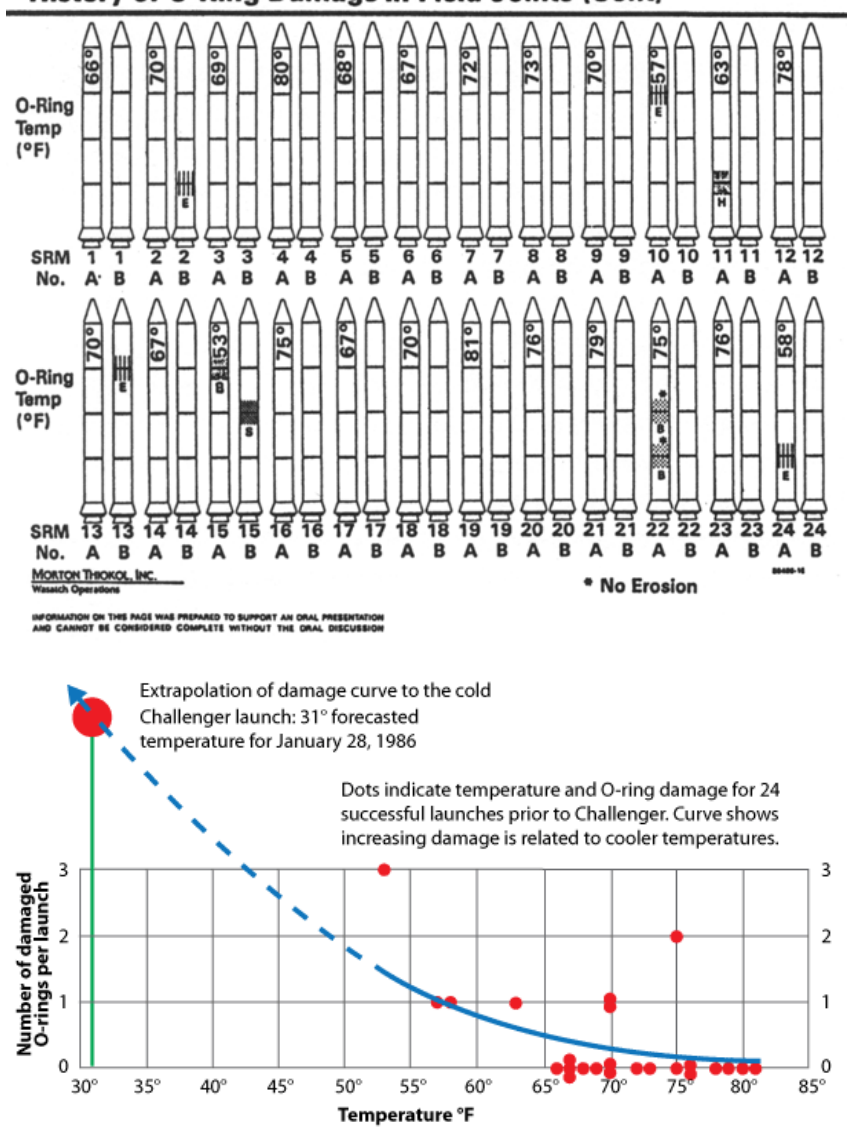

Fig. 3. Classical examples of visual data mining: (a, top): Snow's cholera map, excerpt, showing the Broad Street pump location and the number of deaths per house as bars. Challenger launch temperature and number of damaged O-rings: (b, middle): graphic used by the engineers before the launch, which did not prevent the launch. (c, bottom): proposal by Tufte. ${ }^{10}$ 
6. Data mining sophistication There is none in the algorithmic procedures used; but the visual re-representation can support a (potentially misled) human visual perception of correlations and identify areas where "asking more questions" could be interesting (cf. active learning in machine learning). However, as mentioned above, both tools can support visual data mining.

Further analysis and visualization options are offered by the tool ManyEyes, which will be presented with a focus on its text-analysis capabilities in the following Section.

Visual data mining Visual data mining has been defined as focusing on integrating the user in the KDD process in terms of effective and efficient visualization techniques, interaction capabilities and knowledge transfer. ${ }^{11}$

Well-known examples are two cases explained in detail by Edward Tufte [56]: Snow's Cholera Map, which in the mid-19th century helped to identify polluted water as the source of cholera (by visually correlating a specific water pump with a high incidence of cholera deaths in the neighbourhood), see Fig. 3 (a), or the hypothetical prevention of the 1986 Challenger disaster by the replacement of the actually used, inadequate data visualization, by one that clearly visualizes the intended argument, see Fig. 3 (b) and (c).

\subsection{Analysing language: Viewpoints and bias in media reporting}

Text mining is the application of data mining techniques to texts. This can mean, for example, that classifiers are learned to assign text documents such as Web pages, Twitter messages or even tag sets to a category. These categories may be determined by content (e.g. "sports" vs. "computers", cf. [37]), by opinion polarity (e.g. expressing a positive or a negative opinion about a previously determined topic, cf. [42]), the likely author $[57,20]$, or other criteria.

A criterion that has recently received a lot of attention is "viewpoint" or "bias", as identified by, for example, the (often self-declared) belonging to one of a small set of factions on an issue or even an image-creating identity itself. Examples of the first case are adherents of a political party or members of societal or national groups with pronounced stances on controversial issues (such as Palestinians and Israelis on issues such as Gaza). Examples of the second case are media that represent such stances, such as Al Jazeera on the one hand and Fox on the other. The analysis of, e.g., different lexical choices depending on viewpoint is a classical method in Critical Discourse Analysis, see e.g. [48]. There, however, it is still predominantly done manually and thus on small samples, but corpus-analytic/text-mining methods are gradually beginning to be applied and allow the analysis of a much larger set of documents.

Such analyses are done with supervised learning of global models (e.g., classifier learning), with unsupervised learning of global models (e.g., clustering), or with local-pattern detection (such as frequent phrases).

${ }^{11}$ http://www.dbs.informatik. uni-muenchen.de/Forschung/KDD/VisualDM/, 200101-18, retrieved on $2010-07-26$ 
Table 4: Decision tree for the W1W2 feature set, with previous wrapper feature subset selection (accuracy: $80.56 \%$ ).

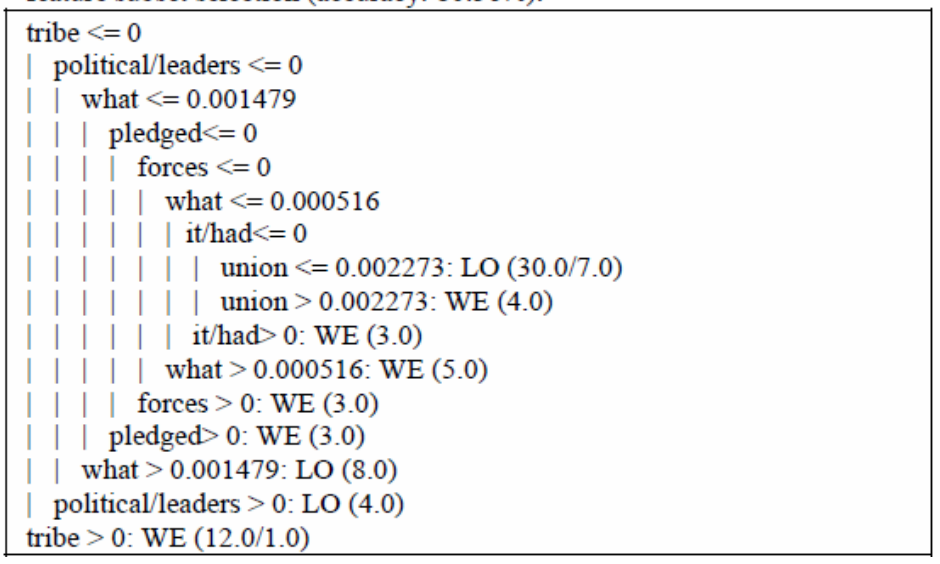

Fig. 4. Decision tree learned to predict LO (local newspaper) vs. WE (Western newspaper), from [46].

Viewpoint mining has so far been explored mostly in research efforts. Supervised modelling typically analyses a topic and then learns a classifier to distinguish between viewpoints on this topic. One example is a media analysis of local vs. Western media reporting on the Kenyan elections; various classification algorithms found, for example, that usage of the word "tribe" was a near-certain predictor of a text having appeared in a Western newspaper [46]. This was found by applying various standard classification-learning algorithms such as decision trees, see Fig. 4.

In [31], a language model of documents for two viewpoint categories was learned; the results were visualized in a tag cloud where size shows frequency and colouring typicality of one of the two viewpoints, see Fig. 5.

In [19], two coarse-grained viewpoints (documents either published by $\mathrm{Al}$ Jazeera or CNN) were input as data labels; based on them, topics were learned in an unsupervised way alongside words that are typical of how the two viewpoints/media report on these topics. The method relies on (a) nearest neighbour / best reciprocal hit for document matching to identify topics and (b) Kernel Canonical Correlation Analysis and vector operations for finding topics and characteristic keywords for viewpoint characterization. Figure 6 shows two examples.

Unsupervised learning has been employed to identify media bias by [44]. They performed two orthogonal analyses on a large corpus of Dutch newspapers: one that distinguishes between articles published before 9/11 and articles published after it, and a second analysis that distinguishes between five newspapers ranging from quality to popular. The question is how the perception of Islam and Christianity may have changed (or differs between sources); the method is based on lexical co-occurrences. The authors use two types of such 


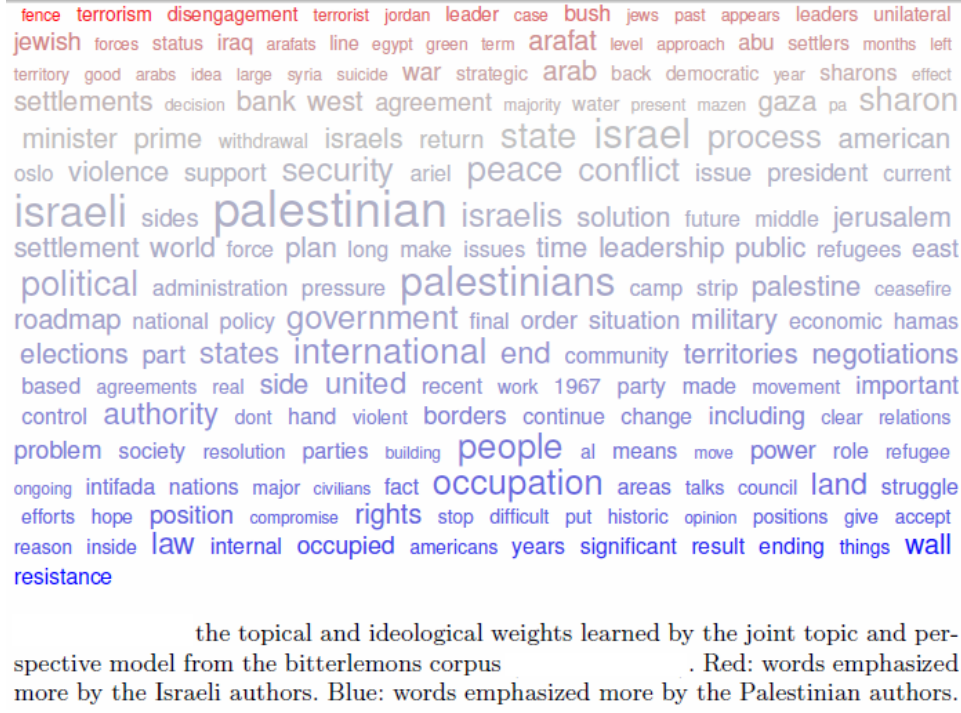

the topical and ideological weights learned by the joint topic and perspective model from the bitterlemons corpus . Red: words emphasized more by the Israeli authors. Blue: words emphasized more by the Palestinian authors.

Fig. 5. Tag cloud showing word frequency and typicality in the two corpora, from [31].

\begin{tabular}{r|l}
\hline ToPIC & Iraq, Baghdad, Hussein, shiite, trials, insurgents, troops \\
\hline CNN & insurgents, Hussein, attorney, Kember, family, British \\
AJ & shia, sunnis, occupation, Saddams, rebels, attack, killed, car \\
\hline \hline ToPIC & Palestinian, Gaza, Israel, Sharon, Hamas, Abbas, militant \\
\hline CNN & militant, Israel, pullout, missiles, launch, Putin, Beirut, jews \\
AJ & settlers, Hamas, barriers, Israeli, clashes, Hezbollah, farms, suffer \\
\hline
\end{tabular}

Fig. 6. Two example topics with the words characterising the topic as a whole and those specific for the two sources, from [19]. 
Table 1. The ten highest climbers in the list of nearest neighbors to islam and christendom after $9 / 11$ for the syntax-based model

\begin{tabular}{ll}
\hline islam & christendom \\
\hline terrorisme 'terrorism' & rechtsstaat 'constitutional state' \\
koran 'Quran' & jodendom 'Judaism' \\
moderniteit 'modernity' & burgerschap 'citizenship' \\
islamist 'islamist' & moderniteit 'modernity' \\
verzorgingsstaat 'welfare state' & hindoeïsme 'Hinduism' \\
religie 'religion' & christen 'Christian' \\
fundamentalist 'fundamentalist' & moraal 'moral' \\
islamiet 'Islamite' & protestante 'Protestant' \\
moslim 'muslim' & fundamentalisme 'fundamentalism' \\
jihad 'jihad' & idealism 'idealism' \\
\hline
\end{tabular}

Fig. 7. Words associated most strongly with the two target words "Christianity" and "Islam", from [44].

word vector space models: one based on co-occurrence in documents (the typical information-retrieval / text-mining vector-space model that is, for example, used in the studies described above), and a syntax-based model that takes into account how frequently two words occur in the same syntactical roles. The target words "Islam" / "Christianity" are described by vectors in these feature spaces, and other words with (cosine-)similar vectors are identified as related in the wider meaning. Some sample results (document- and syntax-based models coincided on the general results) are shown in Fig. 7. In addition, significant differences were found between the newspapers, including a higher co-occurrence of "Islam" and "terrorism" in the most popular newspaper.

However, none of these examples are available in the form of freely accessible and/or Web-based tools; thus they cannot be used easily. In principle, everyone could set up and perform similar mining tasks with the help of the many free tools that exist on the Web; however, the effort needed to pre-process Web documents for mining as well as the expertise needed to operate powerful tools are considerable, such that this is not a realistic option. Individual and taskspecific exceptions confirm this rule, especially in the computational humanities.

One example is the MONK workbench that "includes approximately 525 works of American literature from the 18th and 19th centuries, and 37 plays and 5 works of poetry by William Shakespeare. [...] MONK provides these texts along with tools to enable literary research through the discovery, exploration, and visualization of patterns. Users typically start a project with one of the toolsets that has been predefined by the MONK team. Each toolset is made up of individual tools (e.g. a search tool, a browsing tool, a rating tool, and a 
visualization), and these tools are applied to worksets of texts selected by the user from the MONK datastore. Worksets and results can be saved for later use or modification, and results can be exported in some standard formats (e.g., CSV files)." ${ }^{12}$ The documents in the MONK collection are pre-processed, such that users can concentrate directly on the text-mining tasks. However, the interface is more demanding than, for example, that of GapMinder, such that casual users may be discouraged from experimenting with the tool. An earlier, simpler version of MONK demonstrated the ideas by allowing users to label selected poems by Emily Dickinson as "erotic" or not and then determining, via Naive Bayes learning, which words contributed most to this classification [45].

An example of local pattern mining that is highly accessible are the Word Trees of http://manyeyes.alphaworks.ibm.com/manyeyes/. The method is the discovery of a word (sequence) trie, and the visualization of the sequences with common prefixes together with size indicating frequency. As an example, consider Fig. 8, which shows an analysis of the 2007 resignation speech of US Attorney General Alberto R. Gonzalez. The speech at first glance appears to emphasize his regret over the dismissals of eight attorneys that others claimed he had an important role in, but at second sight looks more self-related.

An analysis along our six principles reveals the following.

1. Situatedness and authenticity, multiple contexts All tools apply text mining to authentic data that are clearly situated as documents from or reporting on current events. Multiple contexts are supported by different datasets, especially in ManyEyes where they can be uploaded by anyone.

2. Active and constructive The interaction and analysis options in MONK provide user activity and choice. Activity is more strongly supported by ManyEyes when users choose their own datasets. A sense of construction can be created in the sense that one transforms texts into graphics; especially in MONK, users can get an idea of the degrees of freedom inherent in making decisions along the different steps of data mining. In addition, the arguments of Section 4.1 apply analogously.

3. Multiple perspectives Multiple perspectives are supported in analogous ways (and for the same reasons) as in the tools presented in Section 4.1.

4. Social This is supported in analogous ways as in the tools presented in Section 4.1. In addition, the uploading of one's own datasets (which can then be re-used by others) can give rise to social usage in ManyEyes.

\footnotetext{
12 http://monkpublic.library.illinois.edu/monkmiddleware/public/index.html

13 http://www.justice.gov/archive/ag/testimony/2007/ag_speech_070419.html; Word Tree generated with http://manyeyes.alphaworks.ibm.com/manyeyes/, retrieved on 2010-07-30.
} 
"... I want to make three brief points about the resignations of the eight United States' attorneys, a topic that I know is foremost in your minds.

First, those eight attorneys deserved better. ... Each is a fine lawyer and dedicated professional. I regret how they were treated, and I apologize to them and to their families for allowing this matter to become an unfortunate and undignified public spectacle. I accept full responsibility for this.

Second, I want to address allegations that I have failed to tell the truth about my involvement in these resignations. These attacks on my integrity have been very painful to me. ..."

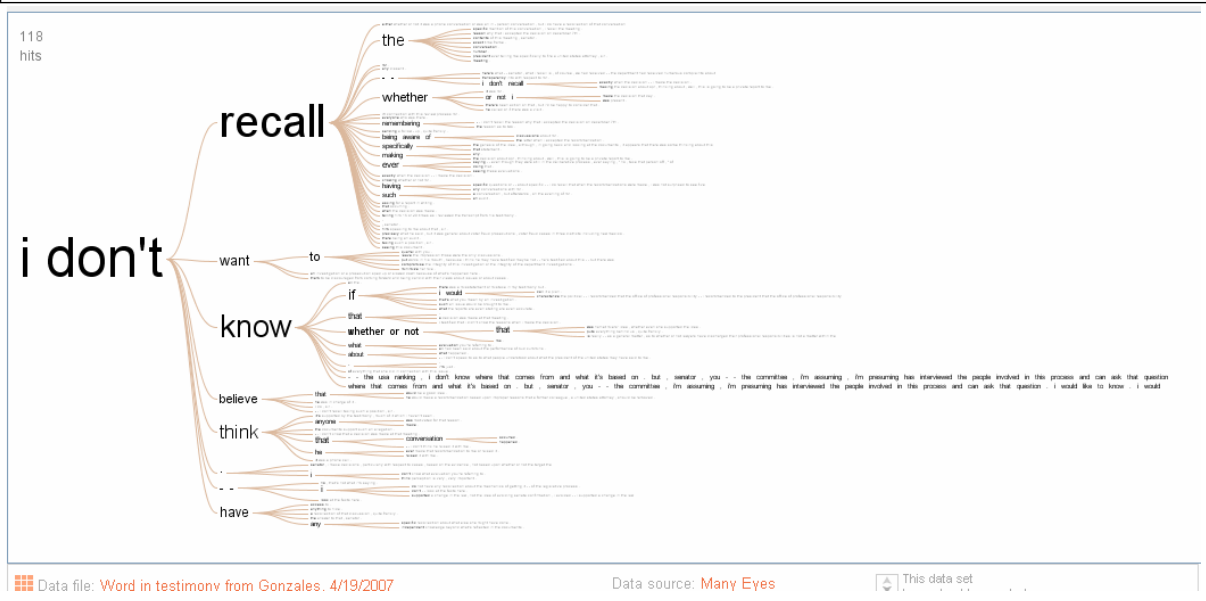

Fig. 8. (top) Excerpts from Gonzalez' resignation speech. (bottom) A Word Tree. ${ }^{13}$ 
5. Articulation and reflection The visualizations and especially the juxtapositions offer re-representations of textual, sentential data; as such, they articulate and re-represent. This happens in various ways: In classifier learning, significant words are extracted that are highly characteristic of a certain category (e.g. viewpoint); in topic detection, "issues" may be discovered (along with typical words common to all reporting on them), and in word trees, frequently used phrases may be discovered. This can arguably be highly conducive to reflection about the connotations of these words or rhetorical effects of these phrases.

6. Data mining sophistication Data mining sophistication ranges from the straightforward application of known algorithms to new problems, to the formulation of new and advanced mining methods. It is likely that freely and flexibly accessible Web-based tools (which are our focus here) will continue to concentrate on straightforward methods; also they are likely to continue concentrating on the application of one type of analysis, since the composition of analysis steps is very demanding for non-experts. (Witness the mixed reception of mashup tools like Yahoo! pipes or its competitors, cf. $[55,15]$.)

\subsection{Analysing data mining: Building, comparing and re-using own and others' conceptualizations of a domain}

Two key elements of the Social Web are complementary: the realization that people are highly different, but that, if brought together by the infrastructure of a worldwide network and appropriate algorithms for finding similarity, many people who are alike (even if they are only 10 worldwide) can profit from each other, and that even more people can profit from others who are only partially alike. ${ }^{14}$ This observation has been utilized in a large number of end-user systems, most notably recommender systems based on various forms of collaborative filtering. Collaborative filtering employs a wide range of sophisticated data-mining techniques, analysing actions (who bought what? who rated what?), content (what are the features of the items people like?) and structures (how do social ties interact with other forms of similarity?). However, the dominant form of presentation of these data-mining results is a focus on the result (with the implicit understanding that this is helpful), and less a focus on how it was reached.

The CiteSeerCluster/Damilicious tool $[10,60]$ is an attempt to use the basic logic of data-mining for a purpose (in this case, the search for scientific literature) to help people reflect on how these results arise and what this means for them - and thus how they may be able to re-use the results. The idea is to help users in sense-making of the results of their literature searches on the Web: on an individual level, by supporting the construction of semantics of the domain described by their search term, and on the collective level, by encouraging users to explore and selectively re-use other users' semantics.

The user can, starting from an automatically generated clustering, group a search result document set into meaningful groups (see Fig. 9), and she can learn

${ }^{14}$ The "long tail" is an expression of these complementary principles in terms of how to produce for and make profit in a world composed of niche markets. 
about alternative groupings determined by other users. To transfer a clustering of one set of documents to another set of documents, the tool learns a model for this clustering, which can be applied to cluster alternative sets of documents. We refer to this model as the clustering's intension ("there is a group of papers dealing with security and privacy"), as opposed to its extension, which is the original, unannotated grouping of the documents ("documents 1, 13 and 35 belong together").

This approach supports various measures of diversity. Such measures can be used to make recommendations and present new, possibly interesting viewpoints of structuring the result set. Specifically, a measure is introduced to quantify the diversity of users, defined on how they have in the past grouped identical sets of resources (here: scientific publications). Two users are maximally diverse if they have imposed orthogonal groupings and minimally diverse if they have imposed the same grouping. By convention, users who have not imposed structure on identical sets of resources could be considered maximally diverse or even as a separate class. A visualization based on this measure of diversity as distance metric and multi-dimensional scaling can then serve to give users a first overview of how "close" others are to them, see the overlaid image at the bottom right of Fig. 9 .

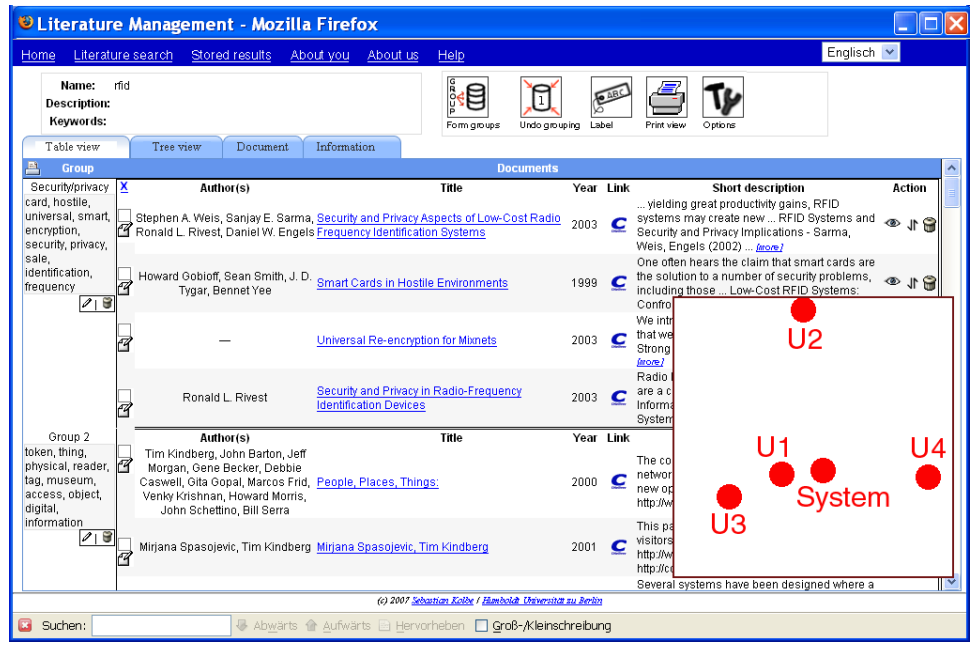

Fig. 9. Main window: User interface for creating one's own grouping and ontology from the search result, from [10]; overlaid image: a visualization of user diversity using multi-dimensional scaling ("System": a user who did not change the system's grouping proposal), from [60].

An analysis according to the six criteria shows the following. 
1. Situatedness and authenticity, multiple contexts The tool supports situated and authentic activities to the extent that literature search is an integral part of the work of an advanced student or other academic. Multiple contexts are only supported to a limited extent (various top-level queries as selectors of the starting set of scientific publications).

2. Active and constructive The tools involves the user strongly in active and constructive sense-making. While users can, in principle, use the tool like a search engine that performs automatic clustering (for example, www.clusty. com), a user study showed that the possibility to re-group is welcomed and used extensively and with good results [10]. Likewise, dealing with user diversity by choosing, for example, very similar users (to be supported in one's ways of thinking) or very dissimilar users (to broaden one's horizon), can be highly constructive and active.

3. Multiple perspectives Damilicious can help users take different perspectives on search results and thereby reflect more deeply about resources on the Web and their meaning.

4. Social The explicit representation of different users can represent a good basis for treating literature search as a social activity. The current version of Damilicious is only a prototype; it therefore needs to be extended by social interaction functionalities such as those of www.citeulike.org or www.bibsonomy.org.

5. Articulation and reflection The interplay between the formation of concept extensions and concept intensions involves constant re-representations, articulations and also reflections of the content concepts of the scientific domain in which literature is being investigated. Similarly, the meta-notion of "people who do (don't) think like me in the sense that they structure the world in the same (different) ways" can serve to articulate the comparatively unreflected notion "people like me" and make it more amenable to reflection.

6. Data mining sophistication The interplay between concept extensions and intensions extends state-of-the-art methods in conceptual and predictive clustering $[4,16] .{ }^{15}$

\subsection{Analysing actions: Feedback and awareness tools}

Doing data or media analyses, as described in the previous sections, probably requires a comparatively deep interest in the phenomena being studied that, for many people, will go beyond a basic need to "be informed". A rather different approach is to take advantage of the liking that many people have to "look into a mirror", where the phenomenon being studied is - them. Feedback and awareness

${ }^{15}$ For a method with similar end results but a different data-mining approach and goals, see [40]. 
tools analyse the log files an individual produces, and compile various statistics about these usage data or run mining analyses on them.

Several such tools have been touted in recent years as enhancers of personal productivity: "time-management software" allow users to see which applications they use for how long, which Web sites they visit and for how long, etc. This can be used as the basis for billing clients. ${ }^{16}$ One site claims that "On average [our tool] recovers 3 hours and 54 minutes worth of productive time per week per person". ${ }^{17}$ These tools generally show users simple statistics such as hours of time spent on Facebook during the last week.

Such self-observation can be useful for learning itself. As studies such as [21] have shown, the support of metacognitive activities that reflect a learning process ex post can improve learning success. Feedback may be given about resource usage and their timing during learning, e.g. in [21], or about the resources used, their semantic classes, and the type of navigation/search between them $[6,5]$.

A recent related development are privacy feedback and awareness tools that are motivated by the increasing revelation and spread of highly personal selfprofiling especially in today's Social Media, and the observation that in spite of many people describing themselves as highly privacy-conscious when asked explicitly, online behaviour differs markedly from these attitudes [7,2]. Alongside this, appeals to be more protective of one's personal data scarcely have any effect; the idea of privacy feedback and awareness tools is to show users within the context of their potentially privacy-related activities (e.g. within their social network platforms) important consequences of activities they have performed.

Privacy awareness tools aim at fostering understanding and reflection: For example, [30] suggest improving privacy sensitivity in systems through feedback that enhances users' understanding of the privacy implications of their system use. This can be coupled with control mechanisms that allow users to conduct socially meaningful actions through them. These ideas have led to suggestions like the identityMirror [33] which learn and visualize a dynamic model of user's identity and tastes. Similar ideas are embodied in the concept of privacy mirrors [38] or in the [24] proposal for linkage control in identity management systems.

Data mining can extend the scope of these applications and simulations for information inference by employing more sophisticated forms of induction and deduction for demonstrating the possible consequences of a user's actions. In [23], we have shown how the spread of visibility/accessibility of a user's profile and relational data may be computed. In the remainder of this section, we first outline how inferencing could be employed in the SNS models we studied and then sketch more sophisticated approaches.

Towards conflict avoidance and resolution: Feedback and negotiation mechanisms The analyses of the cases in [23] have shown, among other things, access permission inconsistencies: some information becomes visible beyond the group of people originally intended. (A simple example is the following that uses

16 http://manictime.com/

${ }^{17}$ http://www.rescuetime.com/ 


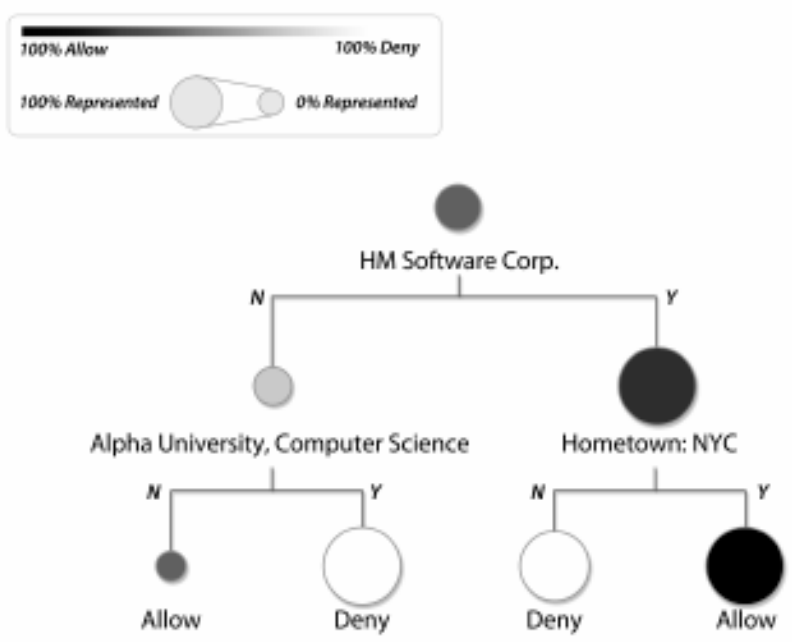

Figure 4: Visualization of Decision Tree Model

Fig. 10. How the current user has decided to share her birthday or not in an online social network based on her friends' features, from [18].

standard social-network functionality: Let $A$ restrict visibility of his friendships to "friends", and let $A$ be friends with $B . B$ sets the visibility of his friendships to "friends-of-friends". Then, a friend $C$ of $B$ 's can, by choosing her friends, determine who gets to see the relationship $A--B$. The recipients may include $D$, with whom $A$ never wanted to share any information.) A "feedback mechanism" could be implemented to make users aware of this. It would signal, upon the intention of users $A$ and $B$ to establish a relation, to them that the actual group of people who will be able to see the relationship will be larger than what they (probably) expect based on their individual permissions.

If such access permission inconsistencies are judged to be acceptable, there is no problem. However, if users disagree, other models will have to be considered that either avoid access permission conflicts or allow users to articulate conflicting requirements and find designs that allow users to negotiate these prior to design or during run-time. It is important to underline the fact that users cannot and do not decide on their preferences alone as long as relational information (such as friendships) and transitive access control (such as the de-facto delegation through access rights for friends etc.) is implemented.

In any case, users should be provided with feedback, informing them about how far their relationship information travels through the graph. This feedback can be coupled with collective privacy setting negotiation mechanisms, building on policy visualization techniques like the Expandable Grids [47]. The intended 
result are better-informed user choices about what information - about themselves or others - to publish and how.

Design choices in feedback mechanisms based on data mining Going beyond straightforward what-if simulations, we believe that feedback for awareness-raising simulations should not only be limited to the application of data-mining models such as classifiers or graph inference results. Rather, it is vital to consider also the dynamics with which users' data-related activities contribute to the learning of these models. Thus, we propose to integrate data mining more fully - by considering also statistical information, by considering also the learning stages of a model - into creating privacy awareness tools.

As one example in social networks, consider the problem of inserting structure into the set of "friends". In current SNS, these sets have no internal structure, or friends can be assigned to predefined classes [12]. These sets grow too fast for many users and easily become unmanageable. This is reminiscent of the email structuring problem (which has been addressed by several machine-learning approaches such as [16]). In addition, it is however an increasing privacy problem, because profile and relational information is distributed either to all friends or to none. To improve on this situation, the user's set of "friends" could be clustered by connectivity, a classifier could be learned from the user's own past communication behavior with these different clusters, and a recommender could be derived from it to suggest that in the future, it might be advisable to withhold certain information from this group. Such mechanisms were implemented in [22] based on tie strength characterized by multiple dimensions representing trust and closeness among friends, and in [18], which also showed that friends' connectivity patterns are a better predictor than these friends' profile information for the willingness to share certain information. This type of clustering / classification / recommendation mining could be incremental, such that the effects of decisions such as accepting an invitation to become friends attain visibility.

This basic idea gives rise to a number of choices and questions: (a) The implications could be shown to users in pull or push fashion. Push has the advantage of potentially reaching more people, but the disadvantage of potentially becoming tiresome and ignored if too many warnings are issued. Machine learning could in turn be used to learn how and when to make proposals to a user to maximize effectiveness (cf. earlier work on desktop agents). (b) Inferences can be based on already-stored data or on what-if simulations. The latter have the advantage of warning people "before it's too late", but may therefore also create a false sense of security. This tradeoff remains an open issue for interaction design. (c) The target groups to whom inferences are shown can range from end users (natural persons in SNS applications, businesses in applications like [8]) to SNS providers. (d) Due to the interdependencies between users and the external effects of their decisions, mechanisms may need to address groups rather than individuals. The challenge then lies in how to best address groups rather than individuals only. Some of the issues involved (such as preference aggregation) will be similar to 
those in issuing recommendations to groups [27], but further ones will surface due to the as-yet little-explored nature of privacy seen as a collective good.

An analysis according to the six criteria shows the following.

1. Situatedness and authenticity, multiple contexts All tools apply data mining to authentic data that are clearly situated as documents from or reporting on the user's own actions. Multiple contexts are supported to the extent that data are collected in multiple work or life contexts. (However, it is an unexplored topic how these contexts should be kept apart.)

2. Active and constructive Activity and constructiveness are similar to those in the tools described in Section 4.1: Users can create representations, but they are limited to the given analysis options. In addition, by being the ones who create the data (by their actions), users can become active in new ways, for example trying out different behaviours. Thus, these tools may have a stronger feedback effect on behaviour.

3. Multiple perspectives In principle, different analysis options could support multiple perspectives; however, it may be that only one perspective (the user watching herself) is encouraged.

4. Social Feedback and awareness tools may comprise social functionalities of different types. Several time-management tools allow one to see, for example, which applications other users use or how one is ranked based on a given measure relative to others (based on a small social network of tool users).

5. Articulation and reflection The visualizations and especially the juxtapositions offer re-representations of textual, sentential data; as such, they articulate and re-represent: Activity is translated into data (such as number of hours spent with a certain application) or into consequences (such as friendships becoming visible to a certain group of people). This can arguably be highly conducive to reflection about the consequences of one's actions (and action based on it, cf. RescueTimes' claim regarding "rescued" work time).

6. Data mining sophistication Data mining sophistication today mostly ranges from the straightforward depiction of basic data statistics, to the application of known algorithms for purposes such as classifier learning. A continued focus on simpler methods appears likely, for the same reasons as discussed in Section 4.2.

\subsection{Analysing actions: Role reversals in data collection and analysis}

As discussed in the previous section, the privacy of one's activities and data on the Internet are becoming an increasing focus of many efforts to increase

18 http://wearcam.org/domewear/, retrieved on 2010-07-30. 
Conspicuously Concealed Cameras as a deterrence against crime

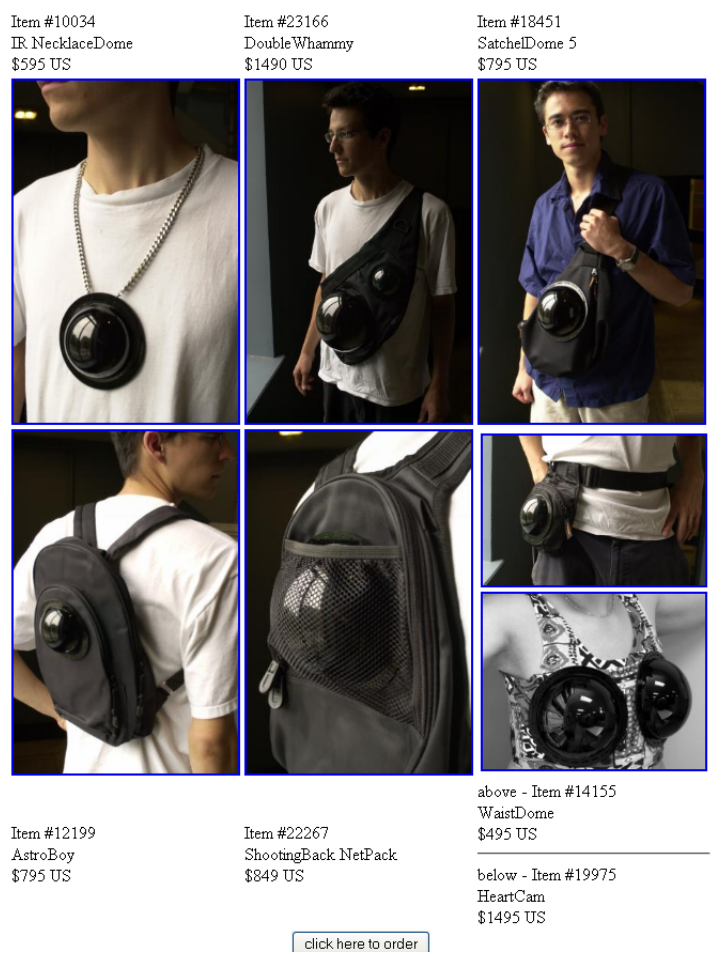

Fig. 11. Sousveillance equipment as high-end consumer goods. ${ }^{18}$ 
information literacy. Here, the notion that 'privacy consists of protecting personal data of individuals' is too narrow to give rise to a true understanding of the dynamics of data disclosure, sharing and hiding. First, as already noticed in the previous section, in richly linked worlds like online social networks, there are many external effects of any one person's privacy-related behaviour. Second, not only individuals have interests in hiding their data; one then speaks of "trade secrets" (when the agent is a business), "national security and classified information" (when the agent is a state), etc.

One of the truisms of information hiding is that it is often used to maintain power. Thus, role reversals may open up discussions of how unequal distributions of information found unequal distributions of power, or even change these power relations.

In the area of collecting data about individuals and groups, often over the Internet, this idea has recently been discussed in the emerging research area of Surveillance Studies [34] under the term sousveillance. Sousveillance is not tied to any particular software and analysis tool; in fact, in line with the focus on data collection, most of the technical attention in this regard is currently focussed on mobile, ubiquitous and wearable devices [35].

Surveillance "is the monitoring of the behavior, activities, or other changing information, usually of people and often in a surreptitious manner. It most usually refers to observation of individuals or groups by government organizations." [63]

Sousveillance "and inverse surveillance are terms [... that] describe the recording of an activity from the perspective of a participant in the activity. [...] Sousveillance typically involves community-based recording from first person perspectives, without necessarily involving any specific political agenda, whereas inverse-surveillance is a form of sousveillance that is typically directed at, or used to collect data to analyze or study, surveillance or its proponents (e.g., the actions of police at a protest rally)." [62]

Just as privacy mirrors can be made more powerful by data mining (see previous section), sousveillance activities are conceivable that involve not only data collection, but also data analysis. A prime example of this is the Wikiscanner ${ }^{19}$, developed by Virgil Griffith: It "allows users to automatically track anonymous edits that people make to Wikipedia entries and trace them to their source. It does so by taking the IP address of the anonymous person who made the Wikipedia changes and identifying who owns the computer network from which the person made the edits.

The tool exposed how insiders at Diebold Election Systems, Exxon, the Central Intelligence Agency and other companies and organizations were surrepti-

$\overline{19}$ http://wikiscanner.virgil.gr/ 
tiously deleting or changing information that was unflattering to them or contradicted the company line." $[65]^{20} 21$

\begin{tabular}{|l|l|l|l|l|}
\hline Article & $\begin{array}{l}\text { IP owner } \\
\mathbf{( 2 0 0 7 )}\end{array}$ & Date & Kind & $\begin{array}{l}\text { Duration } \\
\text { of stay in } \\
\text { Wikipedia }\end{array}$ \\
\hline $\begin{array}{l}\text { Food and } \\
\text { Drug Admin- } \\
\text { istration }\end{array}$ & Fresenius AG & $2004-11-04$ & $\begin{array}{l}\text { reproach that the US Food and } \\
\text { Drug Administration abuses secu- } \\
\text { rity means as a trade impediment }\end{array}$ & $>2$ years \\
\hline $\begin{array}{l}\text { Nuclear } \\
\text { power station } \\
\text { Biblis }\end{array}$ & RWE 22 & $\begin{array}{l}2006-06-30 \\
\text { (not only) }\end{array}$ & $\begin{array}{l}\text { "Biblis is a milestone in terms of } \\
\text { security" etc. }\end{array}$ & 10 min \\
\hline $\begin{array}{l}\text { Clopidogrel } \\
\text { recommendation of S.-A.'s own in- } \\
\text { gredient, downplaying of risks }\end{array}$ & $\begin{array}{l}\text { Sanofi- } \\
\text { Aventis }\end{array}$ & $2007-03-20 \mathrm{~h}$ \\
\hline $\begin{array}{l}\text { The Great } \\
\text { Global } \\
\text { Warming } \\
\text { Swindle }\end{array}$ & $\begin{array}{l}\text { IP of the } \\
\text { German }\end{array}$ & $2007-04-18$ & $\begin{array}{l}\text { removal of factual criticism, as- } \\
\text { cription of lobbying to critics }\end{array}$ & $<1 \mathrm{~min}$ \\
\hline
\end{tabular}

Table 1. Remarkable Contributions to the German-Language Wikipedia, excerpt. ${ }^{23}$

An analysis according to the six criteria shows the following.

1. Situatedness and authenticity, multiple contexts All tools apply data analysis to authentic data that are clearly situated as reporting on actions by agents the user is interested in. Many sousveillance activities, in addition, refer to the user's own actions (like keeping a complete log of one's life based on the recorded data). Multiple contexts are supported to the extent that different agents (e.g., governmental or business) and different edited resources are involved.

2. Active and constructive Activity and constructiveness in the Wikiscanner are similar to those in the tools described in Section 4.1: Users can create representations, but they are limited to the given analysis options. More variation appears to be inherent in several sousveillance activities, but this creativity may be limited (at least at present) to relatively computer-/Internet-savvy people.

${ }^{20}$ Interestingly, the Wikiscanner is seldom if at all (a Google search on 2010-08-05 returned no results) mentioned in relation to sousveillance, possibly because the data have already been collected.

${ }^{21}$ The Wikiscanner has also been used to identify and classify authors representing different viewpoints, e.g. Israeli and Palestinian authors of jointly interesting pages [13]. It can thus, as long as IP address spaces can roughly be identified with viewpoints, be used to create corpora for tools such as those described in Section 4.2.

${ }^{23} \mathrm{RWE}$ is a major German electricity/gas/water provider.

${ }^{23}$ http://de.wikipedia.org/w/index.php?title=Wikipedia:WikiScanner\&oldid= 66534749, retrieved on 2010-07-30, own translation. 
3. Multiple perspectives The very idea of sousveillance or role reversals in watching and analysing rests on establishing multiple perspectives. Thus, these approaches present the strongest support for multiple perspectives.

4. Social Sousveillance is an excellent example of a use of technology as a social practice, such that the focus on the technology itself would be too narrow. Thus, Mann et al. [35, p. 337] observe that "[t]he goal of the performances reported here is less to understand the nature of surveillance than to engage in dialogues with front-line officials and customer service personnel at the point-of-contact in semi-public and commercial locations." While the performances reported in that paper were deliberate activities at the interface between research and arts performances, the same holds for more "incidental" occurrences of sousveillance: Recording a situation is only part of the sousveillance process; communicating about this is another part. This makes video- and photo-sharing sites such as YouTube or Flickr important media. ${ }^{24}$ And Web-based communication underlines the close connection between the two forms of observing: "Social software such as Facebook and MySpace aid surveillance by encouraging people to publish their interests and their friendship networks. They also aid sousveillance by making this information available to peer networks as well as to the authorities." [62]

The Wikiscanner itself has no social functionalities, but it has sparked intense debates (including in the Social Web) and, for example, contributed to the collaborative authoring of Wikiscanner result overviews such as that shown in Fig. $1 .^{25}$

5. Articulation and reflection All activities reported on in this section have a strong component of re-representation and articulation: from turning one's life or perceptions into data, to turning anonymous editors into agents with intentionality. And reflection is the prime motivator: "Sousveillance is a form of 'reflectionism,' a term [...] for a philosophy and procedures of using technology to mirror and confront bureaucratic organizations. Reflectionism holds up the mirror and asks the question: 'Do you like what you see?' If you do not, then you will know that other approaches by which we integrate society and technology must be considered." [35, p. 333]

The goal of reflection, in turn, is social, thus linking our criteria 4. and 5.: "Sousveillance disrupts the power relationship of surveillance when it restores a

${ }^{24}$ [continued citation] "For example, police agents provocateur were quickly revealed on YouTube when they infiltrated a demonstration in Montebello, Quebec, against the leaders of Canada, Mexico and the United States (August 2007). When the head of the Quebec police publicly stated that there was no police presence, a sousveillance video showed him to be wrong. When he revised his statement to say that the police provocateurs were peaceful observers, the same video showed them to be masked, wearing police boots, and holding a rock." [62]

${ }^{25} \mathrm{cf}$. for example http://de.wikipedia.org/w/index.php?title=Wikipedia: WikiScanner\&oldid=35921623 vs. http://de.wikipedia.org/w/index.php? title=Wikipedia:WikiScanner\&oldid=35936088 
traditional balance that the institutionalization of Bentham's Panopticon itself disrupted. It is a conceptual model of reflective awareness that seeks to problematize social interactions and factors of contemporary life. It is a model, with its root in previous emancipatory movements, with the goal of social engagement and dialogue." [35, p. 347]

6. Data mining sophistication So far, the sophistication of the automatic analysis of the gathered data is limited. Typical sousveillance activities focus on data collection and/or various, manually configured, transformations of these data $^{26}$ such as the superimposition of various still and video footage [35] or the transposition into a "CyborgLog" comprehensive electronic diary, cf. [4]. The Wikiscanner uses a straightforward data lookup and record linkage algorithm.

Towards privacy literacy In sum, this and the previous section have shown that in a world in which "people are documents too" by virtue of the traces they leave through many of their online and offline activities and of the compilation efforts performed on these data [9], certain aspects of information literacy as formulated in the 1990s have to be re-evaluated. This can be linked best to Shapiro and Hughes' [52] notion of publishing literacy. This should not only include the "ability to format and publish research and ideas electronically", but also to understand the implications of publishing ideas, whether as an intentional publishing activity in the narrow sense or an unintentional trace-leaving activity, and therefore also the "willingness and ability to not publish material on self or others". This should not be designed to make people become paranoid, fear the "privacy nightmare of the Web", and retreat from public life. Rather, it should make people competent players in "privacy as social practice", strategically revealing or hiding information [23].

An interesting question in this context is what role(s) tools such as the Wikiscanner can play in this context. Are they socially liberating tools that expose "villains" who sabotage a common good, or are they invading the privacy of authors who - for whatever reason - wanted to stay anonymous? And what kind of dynamics, in the privacy and other "games", do they cause? Specifically, do they lead to the type of "arms race" that can be observed for example in spamming: as soon as a new method for spam detection is published, spamming methods with a new level of sophistication will be employed, which in turn leads to the development of new methods for their detection, etc.?

\section{$5 \quad$ Summary and conclusions}

The motivation for this paper was to argue that data mining can do more than help businesses find the nuggets of knowledge in their customer databases, and more than fuel useful applications such as search engines or recommender systems, that instead it can be a means to help people better understand, reflect

${ }^{26}$ These transformations are straightforward/non-sophisticated only from the perspective of data mining! 
and influence information and information-producing and -consuming activities that they are surrounded by in today's "knowledge societies". Understanding and performing data mining and other data-analysis activities is, therefore, part of the answer to the question what a person needs to know today to be a fullfledged, competent and literate member of the information/knowledge society.

The answer to that question lies in the knowledge and skills that make up information literacy. Within that wide construct, we chose to focus on critical literacy, the "ability to evaluate critically the intellectual, human and social strengths and weaknesses, potentials and limits, benefits and costs of information technologies" [52] or "[habits] of thought, reading, writing, and speaking which go beneath surface meaning, first impressions, dominant myths, official pronouncements, traditional clichés, received wisdom, and mere opinions, to understand the deep meaning, root causes, social context, ideology, and personal consequences of any action, event, object, process, organization, experience, text, subject matter, policy, mass media, or discourse" [53]. We argued that this way of regarding critical literacy as a social practice rooted in, and dealing with, language, can and should be extended to a social practice involving (technique) and dealing with (object) data analysis, calling the resulting set of skills and knowledge critical data literacy. Like other authors, we regard education as a good setting for acquiring/teaching these skills and knowledge.

We therefore proposed a structuring framework for describing resources and settings designed to foster critical literacy: whether the predominant technique is language or data analysis, and what the primary object is (language, data analysis, data-related activities, or other data). We also proposed conformance with five principles of successful learning as well as the sophistication of the used data-analysis / data-mining procedures as criteria for characterising any resource or setting, in order to have a basis for assessing learning effectiveness and identifying areas for improvement.

We then described a number of examples of (mostly Web-based) tools representing the four types of objects and data analysis as technique. This showed that "data mining for information literacy" exists and is developing fast, and that recent developments call for a new subcategory of information literacy and/or critical literacy: privacy literacy, a construct which itself raises many new questions. It became clear that each example has different foci, strengths and weaknesses, and that these individual efforts are far from constituting a field with common goals or procedures. The analysis also showed that important inspiration for our vision can come from the field of Surveillance Studies and in particular sousveillance frameworks and activities.

This paper is, by design, a high-level vision paper. Much exciting work remains to be done. Major open issues include (a) how to combine the strengths of the examples shown without compounding their weaknesses; (b) how to improve the analysis frame in the light of new findings from the learning sciences; (c) how to progress from the tool-centric view of the present paper to the design of educational activities in formal as well as informal settings; (d) how, within such settings, people of different aspirations, prior knowledge and current learn- 
ing capacities can be addressed; and (e) how to not get lost in a naive belief in the exclusive merits of knowing ever more ("if only students were to also use method X, they would really understand what's going on"), but also consciously and explicitly deal with the limitations of knowledge-centric beliefs and activities. 


\section{References}

1. Edith Ackermann. Piaget's constructivism, Papert's constructionism: What's the difference? In Constructivism: Uses and perspectives in education. Conference proceedings, Geneva: Research Center in Education / Cahier 8 / September, pages 8594, 2001. http://learning.media.mit.edu/content/publications/EA.Piaget\% $20 \_\% 20$ Papert.pdf.

2. Alessandro Acquisti and Jens Grossklags. Privacy and rationality in individual decision making. IEEE Security \& Privacy, 3(1):26-33, 2005.

3. Ryan S.J.D. Baker and Kalina Yacef. The state of educational data mining in 2009: A review and future visions. Journal of Educational Data Mining, 1(1):3-17, 2009.

4. Gordon Bell and Jim Gemmell. Total Recall: How the E-Memory Revolution Will Change Everything. Penguin Group, 2009.

5. B. Berendt. Lernwege und Metakognition. [[Learning paths and metacognition.]] In Brigitte Berendt, H.-P. Voss, and J. Wildt, editors, Neues Handbuch Hochschullehre. [[New Handbook of Higher Education]] (D3.11, pages. 1-34). Berlin: Raabe Fachverlag für Wissenschaftsinformation, 2006.

6. B. Berendt and E. Brenstein. Visualizing individual differences in Web navigation: STRATDYN, a tool for analyzing navigation patterns. Behavior Research Methods, Instruments, $\&$ Computers, 33:243-257, 2001.

7. B. Berendt, O. Günther, and S. Spiekermann. Privacy in e-commerce: Stated preferences vs. actual behavior. Communications of the ACM, 48(4):101-106, 2005.

8. B. Berendt, S. Preibusch, and M. Teltzrow. A privacy-protecting business-analytics service for online transactions. International Journal of Electronic Commerce, 12:115-150, 2008.

9. B. Berendt. You are a document too: Web mining and ir for next-generation information literacy. In Craig Macdonald, Iadh Ounis, Vassilis Plachouras, Ian Ruthven, and Ryen W. White, editors, ECIR, volume 4956 of Lecture Notes in Computer Science, page 3. Springer, 2008.

10. B. Berendt, B. Krause, and S. Kolbe-Nusser. Intelligent scientific authoring tools: Interactive data mining for constructive uses of citation networks. Inf. Process. Manage., 46(1):1-10, 2010.

11. Michael J. A. Berry and Gordon S. Linoff. Data Mining Techniques: For Marketing, Sales, and Customer Relationship Management. Wiley, 2004.

12. Joseph Bonneau and Sören Preibusch. The privacy jungle: On the market for data protection in social networks. In Proc. WEIS 2009, 2009. http://preibusch.de/ publications/social_networks/privacy_jungle_dataset.htm.

13. Erik Borra. Repurposing the wikiscanner, 2007. http://wiki.issuecrawler.net/ twiki/bin/view/Dmi/WikiScanner [13 August 2008].

14. John S. Brown, Allan Collins, and Paul Duguid. Situated cognition and the culture of learning. Educational Researcher, 18(1):32-42, 1989.

15. Paul Browne. Yahoo pipes could do better, 2007. O'Reilly Java Blog, http://www.oreillynet.com/onjava/blog/2007/03/yahoo_pipes_could_ do_better.html, retrieved 2010-07-30.

16. R. Cole and G. Stumme. CEM - a conceptual email manager. In B. Ganter and G. W. Mineau, editors, Proc. ICCS 2000, volume 1867 of LNAI, pages 438-452. Springer, 2000.

17. John Dewey. Democracy and education. Free Press, New York, 1916. 
18. Lujun Fang and Kristen LeFevre. Privacy wizards for social networking sites. In Proc. 19th International Conference on World Wide Web, WWW 2010, 2010.

19. B. Fortuna, C. Galleguillos, and N. Cristianini. Detecting the bias in media with statistical learning methods. In Ashok N. Srivastava and Mehran Sahami, editors, Text Mining: Classification, Clustering, and Applications. Chapman \& Hall/CRC Press, 2007 / in press.

20. Dan Frankowski, Dan Cosley, Shilad Sen, Loren G. Terveen, and John Riedl. You are what you say: privacy risks of public mentions. In Efthimis N. Efthimiadis, Susan T. Dumais, David Hawking, and Kalervo Järvelin, editors, SIGIR, pages 565-572. ACM, 2006.

21. C.A. Gama. Integrating Metacognition Instruction in Interactive Learning Environments. $\mathrm{PhD}$ thesis, University of Sussex, 2004. http://www.dcc.ufba.br/ claudiag/thesis/Thesis_Gama.pdf, retrieved 2010-08-09.

22. Eric Gilbert and Karrie Karahalios. Predicting tie strength with social media. In Proc. CHI '09, 2009.

23. Seda Gürses and Bettina Berendt. The social web and privacy: Practices, reciprocity and conflict detection in social networks. In E. Ferrari and F. Bonchi, editors, Privacy-Aware Knowledge Discovery: Novel Applications and New Techniques. Chapman \& Hall/CRC Press, 2010.

24. Marit Hansen. Linkage control - integrating the essence of privacy protection into identity management. In eChallenges, 2008.

25. Darrell Huff. How to Lie with Statistics. Norton, New York, 1954.

26. Kei Ishii and Bernd Lutterbeck. Unexploited resources of online education for democracy: Why the future should belong to opencourseware. First Monday, 6(11), 2001. http://firstmonday.org/htbin/cgiwrap/bin/ojs/index.php/fm/ article/view/896, retrieved 2010-07-30.

27. Anthony Jameson and Barry Smyth. Recommendation to groups. In Peter Brusilovsky, Alfred Kobsa, and Wolfgang Nejdl, editors, The Adaptive Web, volume 4321 of Lecture Notes in Computer Science, pages 596-627. Springer, 2007.

28. D. Jonassen. Evaluating constructivist learning. Educational Technology, 36(9):2833, 1991.

29. S. P. Lajoie and S. J. Derry, editors. Computers as cognitive tools. Lawrence Erlbaum, Hillsdale, NJ, 1993.

30. Scott Lederer, Jason I. Hong, Anind K. Dey, and James A. Landay. Personal privacy through understanding and personal privacy through understanding and action: Five pitfalls for designers. Personal Ubiquitous Computing, 8(6):440-454, 2004.

31. Wei-Hao Lin, Eric P. Xing, and Alexander G. Hauptmann. A joint topic and perspective model for ideological discourse. In Walter Daelemans, Bart Goethals, and Katharina Morik, editors, ECML/PKDD (2), volume 5212 of Lecture Notes in Computer Science, pages 17-32. Springer, 2008.

32. Bing Liu. Web Data Mining. Exploring Hyperlinks, Contents, and Usage Data. Springer, Berlin etc., 2007.

33. Hugo Liu, Pattie Maes, and Glorianna Davenport. Unraveling the taste fabric of social networks. International Journal on Semantic Web and Information Systems, 2(1):42-71, 2006.

34. David Lyon. Surveillance Studies: an Overview. Polity Press, Cambridge, UK, 2007.

35. Steve Mann, Jason Nolan, and Barry Wellman. Sousveillance: Inventing and using wearable computing devices for data collection in surveillance environments. 
Surveillance $\mathcal{E}$ Society, 1(3):331-355, 2003. http://wearcam.org/sousveillance. pdf, retrieved 2010-07-30.

36. M. McMahon. Social constructivism and the world wide web - a paradigm for learning. In Paper presented at the ASCILITE Conference, 1997. http://www. ascilite.org.au/conferences/perth97/papers/Mcmahon/Mcmahon.html.

37. Dunja Mladenic. Turning yahoo to automatic web-page classifier. In ECAI, pages 473-474, 1998.

38. D.H. Nguyen and E Mynatt. Privacy mirrors: Understanding and shaping sociotechnical ubiquitous computing. Technical report git-gvu-02-16, Georgia Institute of Technology, USA, 2002.

39. Stefan Niggemeier. Chronisch krank [chronically ill], 2010. http://www . stefan-niggemeier.de/blog/chronisch-krank/, retrieved 2010-07-30.

40. Andreas Nürnberger and Aljoscha Klose. Improving clustering and visualization of multimedia data using interactive user feedback. In Proc. of the 9th International Conference on Information Processing and Management of Uncertainty in Knowledge-Based Systems (IPMU 2002), pages 993-999, 2002.

41. S. Ohlsson. Information processing explanations of insight and related phenomena. In M. Keane and K. Gilhooly, editors, Advances in the Psychology of Thinking (Vol. 1), pages 1-44. Harvester-Wheatsheaf, London, UK, 1992.

42. Bo Pang and Lillian Lee. Opinion mining and sentiment analysis. Foundations and Trends in Information Retrieval, 2(1-2):1-135, 2008.

43. S. Papert. Mindstorms. Children, Computers and Powerful Ideas. Basic Books, New York, 1980.

44. Yves Peirsman, Kris Heylen, and Dirk Geeraerts. Applying word space models to sociolinguistics. religion names before and after 9/11. In Dirk Geeraerts, Gitte Kristiansen, and Yves Peirsman, editors, Advances in Cognitive Sociolinguistics, Cognitive Linguistics Research [CLR], pages 111-137. De Gruyter, New York, 2010.

45. Catherine Plaisant, James Rose, Bei Yu, Loretta Auvil, Matthew G. Kirschenbaum, Martha Nell Smith, Tanya Clement, and Greg Lord. Exploring erotics in Emily Dickinson's correspondence with text mining and visual interfaces. In Gary Marchionini, Michael L. Nelson, and Catherine C. Marshall, editors, JCDL, pages 141-150. ACM, 2006.

46. S. Pollack. Exploratory analysis of press articles on kenyan elections: a data mining approach. In Proc. SiKDD, 2009.

47. Robert W. Reeder. Expandable Grids: A User Interface Visualization Technique and a Policy Semantics to Support Fast, Accurate Security and Privacy Policy Authoring. PhD thesis, Carnegie Mellon University, 2008.

48. J.E. Richardson. Analysing Newspapers. Palgrave Macmillan, Houndmills, UK, 2007.

49. I. Roll, V. Aleven, B.M. McLaren, and K.R. Koedinger. Designing for metacognition - applying cognitive tutor principles to the tutoring of help seeking. Metacognition and Learning, 2(2-3):1556-1623, 2007.

50. Cristobal Romero, Sebastian Ventura, Mykola Pechenizkiy, and Ryan Baker, editors. Handbook of Educational Data Mining. CRC Data Mining and Knowledge Discovery Series. Chapman \& Hall, 2010.

51. Richard Sennett. The Fall of Public Man. Knopf, New York, 1977.

52. Jeremy J. Shapiro and Shelley K. Hughes. Information literacy as a liberal art. enlightenment proposals for a new curriculum. Educom Review, 31(2), 1996.

53. Ira Shor. What is critical literacy? Journal for Pedagogy, Pluralism E Practice, 4(1), 1999. http://www.lesley.edu/journals/jppp/4/shor.html. 
54. Ryan Singel. Newly declassified files detail massive fbi data-mining project. Wired, 2009. http://www.wired.com/threatlevel/2009/09/fbi-nsac/, retrieved 201007-30.

55. Krishnan Subramanian. Microsoft kills yahoo pipes competitor, 2009. http:// ww. cloudave.com/link/microsoft-kills-yahoo-pipes-competitor, retrieved 2010-07-30.

56. Edward R. Tufte. Visual Explanations. Images and Quantities, Evidence and Narrative. Graphics Press, Cheshire, CT, 1997.

57. Hans van Halteren. Linguistic profiling for author recognition and verification. In ACL '04: Proceedings of the 42nd Annual Meeting on Association for Computational Linguistics, page 199, Morristown, NJ, USA, 2004. Association for Computational Linguistics.

58. Wouter van Joolingen. Cognitive tools for discovery learning. International Journal of Artificial Intelligence in Education, 10:385-397, 1999.

59. P. Van Meter and R. J. Stevens. The role of theory in the study of peer collaboration. The Journal of Experimental Education, 69:113-127, 2000.

60. M. Verbeke, B. Berendt, and S. Nijssen. Data mining, interactive semantic structuring, and collaboration: A diversity-aware method for sense-making in search. In Proceedings of First International Workshop on Living Web, collocated with the 8th International Semantic Web Conference (ISWC-2009), Washington D.C., USA, October 26, 2009, 2009. CEUR Workshop Proceedings Vol-515, http: //sunsite.informatik.rwth-aachen.de/Publications/CEUR-WS/Vol-515/.

61. L.S. Vygotsky. Mind in society: The development of higher mental processes. Harvard University Press, Cambridge, MA, 1978.

62. Wikipedia contributors. Sousveillance, 2010. http://en.wikipedia.org/w/index . php?title=Sousveillance\&oldid=375690865, retrieved 2010-08-09.

63. Wikipedia contributors. Surveillance, 2010. http://en.wikipedia.org/w/index. php?title=Surveillance\&oldid=376166748, retrieved 2010-08-09.

64. A. Woolfolk. Educational Psychology. Merrill, Upper Saddle River, NJ, $11^{\text {th }}$ edition, 2010.

65. Kim Zetter. Wikiscanner creator releases new tools to uncover anonymous edits. Wired, 2008. http://www.wired.com/threatlevel/2008/07/wikiscanner-cre/, retrieved 2010-07-30. 